\title{
Sequence variability of FrpB, a major iron-regulated outer-membrane protein in the pathogenic neisseriae
}

\author{
Peter van der Ley, Jenny van der Biezen, Roger Sutmuller, \\ Peter Hoogerhout and Jan T. Poolman
}

Laboratory of Vaccine Development and Immune Mechanisms, National Institute of Public Health and the Environment, Antonie van

Leeuwenhoeklaan 9, PO

Box 1, 3720 BA Bilthoven, The Netherlands
Author for correspondence: Peter van der Ley. Tel: +3130 2742533. Fax: +31302744429. e-mail: peterl@rivm.nl
Keywords: Neisseria meningitidis, iron limitation, antigenic variation, outer-membrane vaccine

\section{INTRODUCTION}

Disease caused by Neisseria meningitidis remains a significant public health problem worldwide. At present, there is no vaccine available against group B organisms, which are the predominant cause of meningococcal disease. The use of the group B capsular polysaccharide as a vaccine has been hindered by the presence of identical structures on neural cell adhesion molecules in the human host, raising the possibility of inducing autoimmune pathology with such a vaccine. As an alternative, vaccines based on meningococcal outer membranes are currently under investigation (Diaz Romero \& Outschoorn, 1994; Poolman, 1995; Frasch, 1995). Efficacy trials in humans with such vaccines have demonstrated partial protection against meningococcal disease. They consist of outermembrane vesicles prepared from one particular strain; since many of the major outer-membrane proteins (OMPs) are variable among different strains, a large proportion of the protective antibodies induced will be

\footnotetext{
Abbreviation: OMP, outer-membrane protein.
}

The GenBank accession numbers for the sequences determined in this work are: U55377 (2996), U55378 (892257), U67312 (870227), U67310 (870446), U67314 (M982), U67311 (M990) and U67313 (\$3446). strain-specific. In addition, not all outer-membrane components contribute to the induction of bactericidal antibodies. For these reasons, we are attempting to improve outer-membrane vesicle vaccines, by manipulating the OMP composition of a particular strain (van der Ley \& Poolman, 1992; van der Ley et al., 1995). Since the class 1 protein appears to be an important target for bactericidal antibodies, derivatives of strain H44/76 carrying three copies of the por $A$ gene have been constructed, with each copy encoding an antigenically different form of the class 1 OMP. Expression of the class 3 and 4 OMPs was abolished because these proteins do not contribute much to the induction of bactericidal antibodies and, in the case of class 4 OMP, might even be detrimental due to the induction of blocking antibodies. Other candidates for inclusion are the several OMPs induced by growth under iron limitation, including receptors for such iron sources as lactoferrin, transferrin and haemoglobin (Legrain et al., 1993; Pettersson et al., 1994; Stojilikovic et al., 1995). In particular, the FrpB protein appears to be a good target for bactericidal antibodies (Pettersson et al., 1990). The sequence of this $77 \mathrm{kDa}$ protein shows the characteristics of a TonBdependent outer-membrane receptor; however, no role in iron uptake has yet been demonstrated (Pettersson et al., 1995). Since bactericidal monoclonal antibodies (mAbs) 
isolated against FrpB were found to be strain specific, characterization of the variability of this protein is essential for assessment of its vaccine potential. This study reports the sequence variability of the $f r p B$ gene among a number of different strains, and the mapping of epitopes recognized by bactericidal mAbs.

\section{METHODS}

Bacterial strains. The Neisseria meningitidis group B strains H44/76 (15:P1.7,16), 2996 (2b:P1.5,2), 892257 (4:P1.7 $\left.7^{\mathrm{h}}, 4\right)$, 870227 (4:P1.5 $\left.{ }^{\mathrm{c}}, 10\right), 870446$ (14:P1.12,13), M982 (9:P1.9), M990 (6:P1.6) and S3446 (14:P1.14) were from our own collection and have been described previously (van der Ley et al., 1995). Meningococci were grown overnight at $37^{\circ} \mathrm{C}$ on GC medium base (Difco) supplemented with IsoVitaleX in a humid atmosphere containing $5 \% \mathrm{CO}_{2}$. Escherichia coli strain $\mathrm{INVaF}^{\prime}$ was grown on $\mathrm{LB}$ medium at $37^{\circ} \mathrm{C}$.

Sequence analysis. PCR reactions on meningococcal genomic DNA were performed with AmpliTaq on whole-cell suspensions that had been heated for $10 \mathrm{~min}$ at $95^{\circ} \mathrm{C}$. Primers 4 (5'-GGCTGCAGAGGGTATTGGTCCAGCGTTG-3') and 12 (5'-GCAGAAAATAATGCCAAGGTC-3'), based on the $f r p B$ sequence previously published for strain $\mathrm{H} 44 / 76$, were used in the following programme: 30 cycles of $1 \mathrm{~min}$ at $95^{\circ} \mathrm{C}$, $1.5 \mathrm{~min}$ at $52{ }^{\circ} \mathrm{C}, 2 \mathrm{~min}$ at $72{ }^{\circ} \mathrm{C}$. The resulting PCR products of approximately $2.0 \mathrm{~kb}$ were cloned into the plasmid vector pCRII using the TA cloning kit of Invitrogen. Plasmid DNA was purified after alkaline lysis on Qiagen columns. Sequence analysis was performed with an Applied Biosystems automatic sequencer on double-stranded plasmid DNA templates, with the Taq Dye Deoxy Terminator Cycle Sequencing Kit and frpBspecific primers. Sequences were established for both strands and with at least two independent clones.

Peptide ELISA. Biotinylaminohexyl peptides were synthesized using an automated multiple peptide synthesizer (Wiertz et al., 1992). They were bound to avidin-coated microtitre plates and used in an ELISA as described by Pettersson et al. (1994). The bactericidal mAbs directed against FrpB from strain H44/76 (mn70K1, mn70K2, mn70K3, mn70K5, mn70K6 and mn70K7) and strain 2996 (A1A-A2 and 4F3-E5) have been described previously (Pettersson et al., 1990, 1991).

\section{RESULTS AND DISCUSSION}

\section{Sequence of the frpB gene in different meningococcal strains}

In a previous study, FrpB-specific mAbs with bactericidal activity against either strain $\mathrm{H} 44 / 76$ or strain 2996 were described. Most strains from a collection of 74 failed to react with any of these antibodies, suggesting a high degree of antigenic heterogeneity in this protein (Pettersson et al., 1990). The frpB gene from strain H44/76 has been sequenced previously (Pettersson et al., 1995); we now report the complete sequences for strains 2996 and 892257 . Since the latter strain is not recognized by any of the isolated mAbs, its FrpB protein must represent a third antigenic type. In Fig. 1, a comparison is given of the resulting three meningococcal sequences with the FrpB sequence that was reported for the gonococcal strain FA19 (Beucher \& Sparling, 1995). The overall homology varies from 91 to $94 \%$, with the most pronounced

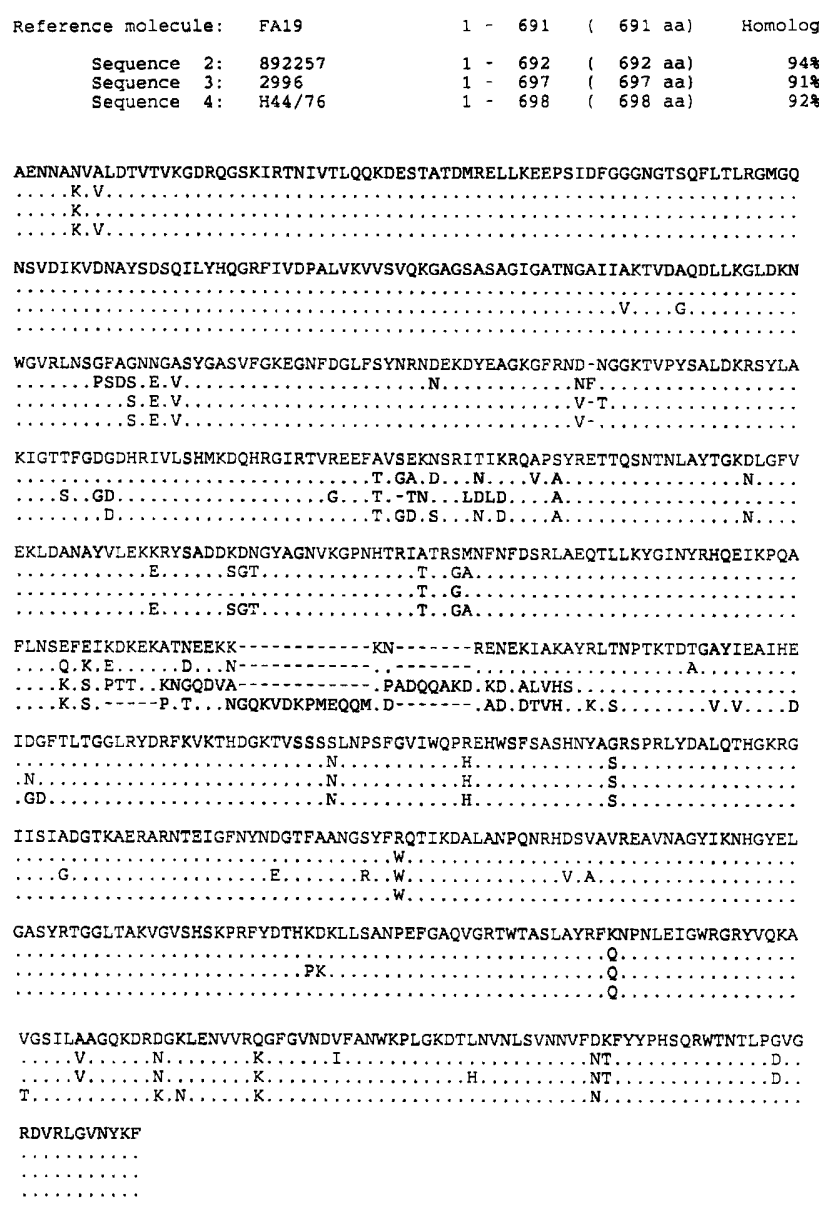

Fig. 1. Sequence comparison of the mature FrpB protein from Neisseria gonorrhoeae strain FA19 (Beucher \& Sparling, 1995) and Neisseria meningitidis strains 892257, 2996 and H44/76 (Pettersson et al., 1995; this study).

sequence variation confined to the region from residues 350 to 390 . In a model for the topology of FrpB in the outer membrane, 13 surface-exposed loops were predicted (Pettersson et al., 1995). The longest of these, loop 7, corresponds to this region of highest sequence variation (Fig. 2). Most of the other, shorter, polymorphic regions are also located in surface-exposed loops of the model; particularly great variability is also found within the predicted loop 5, the second-largest loop. An exception is the variable region around residue 150 , which is predicted to be at the periplasmic side. Remarkably, the loop 7 sequence from strain 892257 is highly similar to the gonococcal sequence but very different from those of the two other meningococcal strains. However, in the rest of the sequence the similarity between the meningococcal strain 892257 and the gonococcal strain FA19 is not particularly close. This situation is reminiscent of the por $A$ gene, where a mosaic structure has been interpreted as evidence for horizontal gene transfer among different meningococcal strains by means of genetic transformation (Feavers et al., 1992). Interspecies transfer of chromosomal genes between $N$. meningitidis and $N$. gonorrboeae has been suggested for the $\operatorname{tb} p A / B$ and $p o r B$ genes 


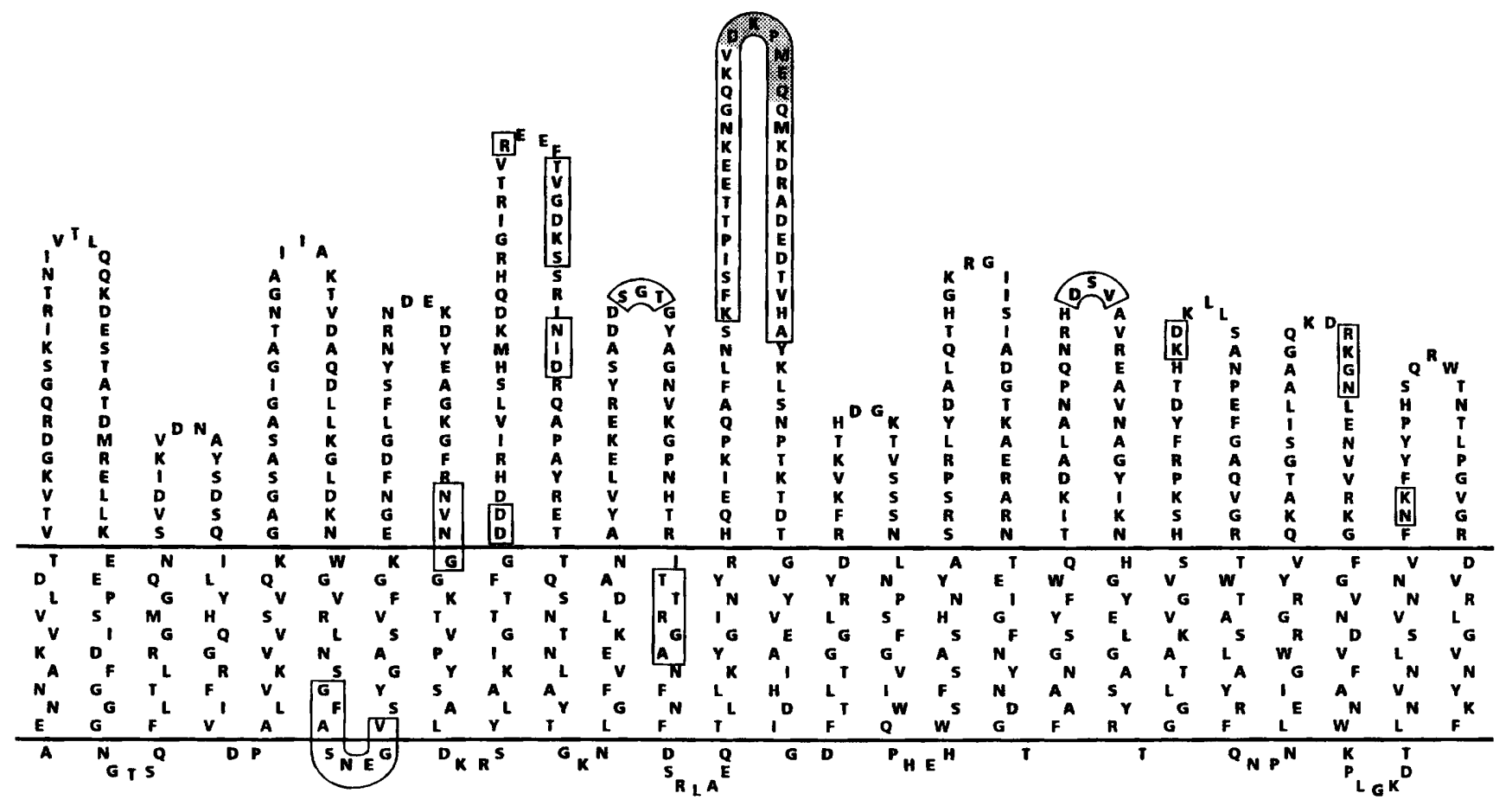

Fig. 2. Topology of FrpB from strain $H 44 / 76$ in the outer membrane (taken from Pettersson et al., 1995). The most variable regions are boxed. The minimal sequence essential for binding of bactericidal mAbs is shaded.

(Cornelissen \& Sparling, 1994; Vázquez et al. 1995), encoding the transferrin receptor and the major porin, respectively. In both cases, meningococcal sequences were found that are much closer to a gonococcal sequence than to other meningococcal strains. In the case of $f r p B$, a relatively recent exchange of the loop 7 region between ancestors of gonococcal strain FA19 and meningococcal strain 892257 is likely.

\section{Location of epitopes recognized by FrpB-specific mAbs}

Since loop 7 in the FrpB topology model is both the longest surface-exposed loop and the region with the most pronounced sequence variation, it seemed likely that this would also constitute an important target for antibodies. Previously, six bactericidal $\mathrm{mAbs}$ specific for FrpB from strain H44/76, and two against strain 2996, have been described (Pettersson et al., 1990, 1991). In order to map their epitopes, their binding to synthetic peptides derived from the loop 7 sequence was investigated. Four 18-residue peptides with a 12-residue overlap were synthesized from both the H44/76 and the 2996 sequences (Fig. 3), and $\mathrm{mAb}$ binding was measured by ELISA (Fig. 4, Table 1). Two of the four H44/76 peptides were recognized by three $\mathrm{mAbs}$, the first peptide giving the strongest reactivity. In the case of the four 2996 peptides, only the first one was recognized by one mAb. The first peptides correspond to the top of loop 7, showing that this is indeed a likely epitope for bactericidal
H44/76 loop 7 peptides:

$\begin{array}{ll}\text { KNGQKVDKPMEQQMKDAA } & 124 \mathrm{E} 2 \\ \text { DKPMEQQMKDRADEDTVH } & 124 \mathrm{A3} \\ \text { QMKDRADEDTVHAYKLSN } & 124 \mathrm{A2} \\ \text { DEDTVHAYKLSNPTKTDT } & 124 \mathrm{C} 2\end{array}$

2996 loop 7 peptides:

KNGQDVAKPADQQAKDRK 124D2

AKPADQQAKDRKDEALVH $124 \mathrm{~F} 2$

QAKDRKDEALVHSYRLTN 124F1

DEALVHSYRLTNPTKTDT $124 \mathrm{~B} 2$

Fig. 3. Synthetic overlapping peptides based on the loop 7 sequence of FrpB from strains H44/76 and 2996.

$\mathrm{mAbs}$. The remaining $\mathrm{mAbs}$ might be specific for another loop in $\mathrm{FrpB}$, or for a particular sequence and/or conformation in loop 7 that is not represented by the four peptides. However, it should be noted that all these mAbs can bind to denatured FrpB in a Western blot.

\section{Sequence variation in the loop 7 region of FrpB}

As described above, loop 7 in the FrpB topology model contains both a highly variable part of the protein and the epitopes for a number of bactericidal mAbs. In order to gain more insight into the degree of interstrain variation 

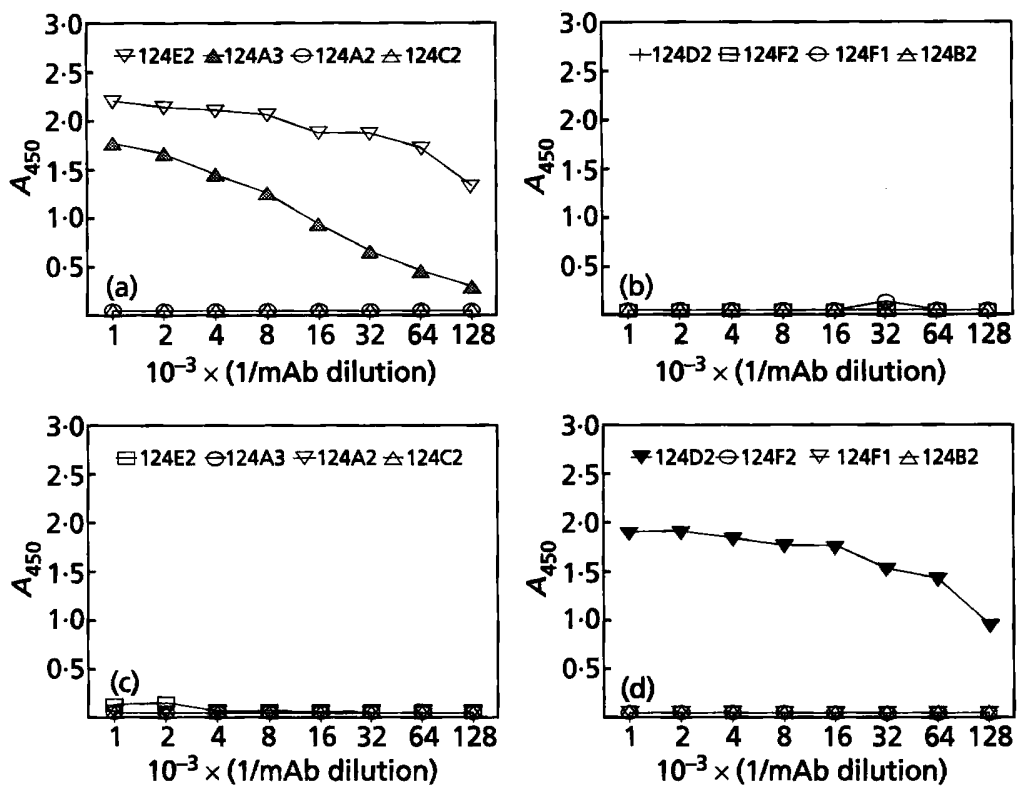

Fig. 4. Binding of FrpB-specific mAbs mn70K1 and 4F3-E5 to synthetic peptides derived from the loop 7 sequence of strain $\mathrm{H} 44 / 76$ and 2996. ELISA reactivity is expressed as $A_{450}$. (a, b) mn70K1 against H44/76 peptides (a) and 2996 peptides (b); (c, d) 4F3-E5 against H44/76 peptides (c) and 2996 peptides (d). Two other mAbs (mn70K2 and $\mathrm{mn} 70 \mathrm{~K} 3)$ gave results similar to mn70K1; the remaining four (three against $\mathrm{H} 44 / 76$ and one against 2996) failed to react with any of the peptides.

Table 1. Binding of FrpB-specific mAbs to synthetic peptides corresponding to loop 7

The results are based on ELISA reactivity as shown in Fig. 4.

\begin{tabular}{|c|c|c|c|c|c|c|c|c|}
\hline \multirow[t]{2}{*}{$\mathbf{m A b}$} & \multicolumn{4}{|c|}{ H44/76 peptides } & \multicolumn{4}{|c|}{2996 peptides } \\
\hline & 124E2 & $124 \mathrm{A3}$ & $124 \mathrm{~A} 2$ & $124 \mathrm{C} 2$ & $124 \mathrm{D} 2$ & 124F2 & $124 \mathrm{~F} 1$ & $124 B 2$ \\
\hline $\mathrm{mn} 70 \mathrm{~K} 1$ & ++ & + & - & - & - & - & - & - \\
\hline $\mathrm{mn} 70 \mathrm{~K} 2$ & ++ & + & - & - & - & - & - & - \\
\hline $\mathrm{mn} 70 \mathrm{~K} 3$ & ++ & + & - & - & - & - & - & - \\
\hline $\mathrm{mn} 70 \mathrm{~K} 5$ & - & - & - & - & - & - & - & - \\
\hline $\mathrm{mn} 70 \mathrm{~K} 6$ & - & - & - & - & - & - & - & - \\
\hline $\mathrm{mn} 70 \mathrm{~K} 7$ & - & - & - & - & - & - & - & - \\
\hline $\mathrm{A} 1 \mathrm{~A}-\mathrm{A} 2$ & - & - & - & - & - & - & - & - \\
\hline 4F3-E5 & - & - & - & - & ++ & - & - & - \\
\hline
\end{tabular}

within this immunologically important part of $\operatorname{FrpB}$, its sequence was determined for five other meningococcal strains, each representing a different porin serotype/ subtype. A region of approximately 100 amino acid residues around loop 7 is shown for all eight strains in Fig. 5. Pairwise comparisons show variable levels of similarity (Table 2). Two sequences are identical (2996 and 870446) and two others are nearly so (870227 and S3446). However, even when a relatively high degree of similarity is found, the proteins can still be antigenically different, as is the case for strains $\mathrm{H} 44 / 76$ and 2996. In this set of strains, there is no correlation between serotype/subtype on the one hand, and FrpB loop 7 sequence on the other. For instance, both strains 870446 and S3446 are serotype 14, but have highly different loop 7 sequences. The identical loop 7 sequences in strains 2996 and 870446 are found in combination with completely different serotype/ subtype, i.e. $2 \mathrm{~b}: \mathrm{P} 1.5,2$ and $14: \mathrm{P} 1.12,13$ respectively. This again indicates horizontal transfer of por $A / B$ and/or frp $B$ alleles among different strains.

\section{Conclusions}

In this study, sequence analysis and epitope mapping of the meningococcal FrpB protein have been used to demonstrate that the longest surface-exposed loop in the previously proposed topology model is both hypervariable and a target for bactericidal mAbs. A similar correlation has also been found for the neisserial porins (van der Ley et al., 1991). In the case of the gonococcal PIA porin, statistical analysis of synonymous and nonsynonymous substitutions has been used to infer positive Darwinian selection for diversity in the surface-exposed loops, driven by the human immune system (Smith et al., 1995). Considering the very high variability of loop 7 of FrpB, it is tempting to speculate that this not only has the 


\begin{tabular}{|c|c|c|c|c|c|c|c|c|}
\hline Reference molecu & le: & $\mathrm{H} 44 / 76$ & 1 & -105 & 1 & 105 & aa) & Homology \\
\hline Sequence & 2: & 2996 & 1 & -105 & 1 & 105 & aa) & $83 \%$ \\
\hline Sequence & 3: & 870446 & 1 & 105 & $i$ & 105 & aa) & $83 \%$ \\
\hline Sequence & 4: & 892257 & 1 & 98 & $i$ & 98 & aa) & 708 \\
\hline Sequence & 5: & M990 & 1 & 98 & ( & 98 & aa) & 768 \\
\hline Sequence & 6: & 870227 & 1 & - 108 & $i$ & 108 & aa) & $73 \%$ \\
\hline Sequence & $7:$ & S3446 & 1 & -108 & 1 & 108 & aa) & 738 \\
\hline Sequence & 8: & M982 & 1 & $-\quad 108$ & $i$ & 108 & aa) & 708 \\
\hline
\end{tabular}

\begin{tabular}{|c|c|c|}
\hline H44/76 & PNHTRITTRGANFNFDSRLAEQTLLKYGINYRHQEIKPQAFLNSKFSIP- & 49) \\
\hline 2996 & 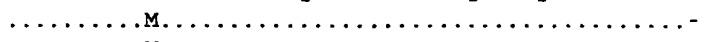 & 49) \\
\hline 870445 & $\ldots \ldots \ldots \ldots$ м. & 49) \\
\hline 892257 & 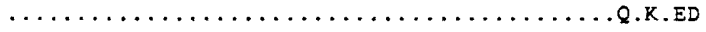 & 50) \\
\hline M990 & $\ldots \ldots \ldots \ldots$ м............... & 48 \\
\hline 870227 & 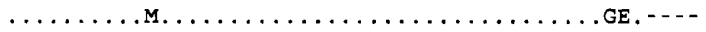 & 46 \\
\hline$\$ 3446$ & $\ldots \ldots \ldots \ldots \ldots \ldots \ldots \ldots \ldots \ldots \ldots \ldots \ldots$ GE. $^{--}$ & 46) \\
\hline M982 & $\ldots \ldots \ldots$ M. . . . . . . . . . . & 49) \\
\hline $\mathrm{H} 44 / 76$ & - - TTEEKNGQKV - - D- - - - - KPMEQQMKDRADEDTVHAYKLSN & 83 \\
\hline 2996 & $\ldots \ldots$ K. . D, & ( 83) \\
\hline 870446 & - . K. . . D. - A - . A A . A. K. AL.S.R.T. & $(83)$ \\
\hline 892257 & KEKA.D.......... EN.KIAK. R.T. & 76 \\
\hline M990 & - D.T. - A - A.I. .N. . A.A.D. . & 76 \\
\hline 870227 & 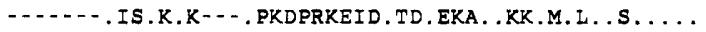 & 186 \\
\hline$\$ 3446$ & - - . IS.K.K- . PKDPKXEID.TA.EKA. KK.M.I..S... & 86) \\
\hline M982 & - - DKKRNPANPKEEI. $\cdots$ & 86) \\
\hline $\mathrm{H} 44 / 76$ & PTKTDTGVYVEAIHDIGDFTLT & \\
\hline 2996 & ...........E.NG... & \\
\hline 870446 & .....A.I...E.NG... & \\
\hline 892257 & ....A.A.I...E.DG. . & \\
\hline M990 & ....A.I.T.E.G... & \\
\hline 870227 & ........T.E..G... & \\
\hline 53446 & .....A.I.T.E.DG. . . & \\
\hline M982 & .А........ ....... & \\
\hline
\end{tabular}

Fig. 5. Sequence comparison of the loop 7 region of FrpB from eight different meningococcal strains. The H44/76 sequence is used as the reference.

Table 2. Similarity matrix of the FrpB loop 7 region from eight different strains

The results show percentage homology for the sequences in Fig. 5, allowing for conservative substitutions.

\begin{tabular}{|l|rrrrrrrr|}
\cline { 2 - 9 } \multicolumn{1}{c|}{} & H44/76 & $\mathbf{2 9 9 6}$ & $\mathbf{8 7 0 4 4 6}$ & $\mathbf{8 9 2 2 5 7}$ & $\mathbf{M 9 9 0}$ & $\mathbf{8 7 0 2 2 7}$ & S3446 & M982 \\
\hline $\mathbf{H 4 4 / 7 6}$ & & 90 & 90 & 80 & 80 & 81 & 82 & 84 \\
$\mathbf{2 9 9 6}$ & 90 & & 100 & 80 & 82 & 86 & 85 & 88 \\
$\mathbf{8 7 0 4 4 6}$ & 90 & 100 & & 80 & 82 & 86 & 85 & $\mathbf{8 8}$ \\
$\mathbf{8 9 2 2 5 7}$ & 85 & 85 & 85 & & 87 & 87 & 89 & 87 \\
$\mathbf{M 9 9 0}$ & 86 & 88 & 88 & 88 & & 84 & 82 & 85 \\
$\mathbf{8 7 0 2 2 7}$ & 78 & 82 & 82 & 79 & 76 & & 97 & 89 \\
$\mathbf{S 3 4 4 6}$ & 79 & 82 & 82 & 81 & 74 & 97 & & 88 \\
$\mathbf{M 9 8 2}$ & $\mathbf{8 1}$ & 85 & 85 & 79 & 78 & 89 & 89 & \\
\hline
\end{tabular}

same basis, but might even be the function of this part of the protein, i.e. a highly exposed immune 'decoy' to protect other more conserved and functionally important surface-exposed loops. Although a function for FrpB in iron uptake has not yet been demonstrated, its homology to other TonB-dependent outer-membrane receptors strongly suggests that it must function as a receptor for some iron source or other compound that is required under conditions of iron limitation. It is unlikely that such a highly variable sequence as loop 7 could be directly involved in this presumed receptor function. The fact that in our limited set of eight strains there is already a high degree of FrpB sequence variation makes it unlikely that a vaccine based on the variable part of this protein could ever be effective. This contradicts earlier studies suggesting that FrpB is antigenically conserved (Black et al., 1986; Banerjee-Bhatnagar \& Frasch, 1990). As an alternative, one could study the immunogenicity of mutant versions of FrpB lacking part of loop 7, to see if that makes it possible to induce bactericidal antibodies against other, more conserved loops.

\section{REFERENCES}

Banerjee-Bhatnagar, N. \& Frasch, C. E. (1990). Expression of Neisseria meningitidis iron-regulated outer-membrane proteins, including a 70-kilodalton transferrin receptor, and their potential for use as vaccines. Infect Immun 58, 2875-2881. 
Beucher, M. \& Sparling, P. F. (1995). Cloning, sequencing and characterization of the gene encoding $\mathrm{FrpB}$, a major iron-regulated, outer-membrane protein of Neisseria gonorrboeae. J Bacteriol 177, 2041-2049.

Black, J. R., Dyer, D. W., Thompson, M. K. \& Sparling, P. F. (1986). Human immune response to iron-repressible outer-membrane proteins of Neisseria meningitidis. Infect Immun 54, 710-713.

Cornelissen, C. N. \& Sparling, P. F. (1994). Iron piracy : acquisition of transferrin-bound iron by bacterial pathogens. Mol Microbiol 14, 843-850.

Diaz Romero, J. \& Outschoorn, I. M. (1994). Current status of meningococcal group $B$ vaccine candidates: capsular or noncapsular? Clin Microbiol Rev 7, 559-575.

Feavers, I. M., Heath, A. B., Bygraves, J. A. \& Maiden, M. C. J. (1992). Role of horizontal genetic exchange in the antigenic variation of the class 1 outer-membrane protein of Neisseria meningitidis. Mol Microbiol 6, 489-495.

Frasch, C. E. (1995). Meningococcal vaccines: past, present and future. In Meningococcal Disease, pp. 245-283. Edited by K. Cartwright. Chichester: John Wiley.

Legrain, M., Mazarin, V., Irwin, S.W., Bouchon, B., QuentinMillet, M.-J., Jacobs, E. \& Schryvers, A. B. (1993). Cloning and characterization of Neisseria meningitidis genes encoding the transferrin-binding proteins Tbp1 and Tbp2. Gene 130, 73-80.

van der Ley, P. \& Poolman, J. T. (1992). Construction of a multivalent meningococcal vaccine strain based on the class 1 outer-membrane protein. Infect Immun 60, 3156-3161.

van der Ley, P., Heckels, J. E., Virji, M., Hoogerhout, P. \& Poolman, J. T. (1991). Topology of outer-membrane porins in pathogenic Neisseria spp. Infect Immun 59, 2963-2971.

van der Ley, P., van der Biezen, J. \& Poolman, J. T. (1995). Construction of Neisseria meningitidis strains carrying multiple chromosomal copies of the por $A$ gene for use in the production of a multivalent outer membrane vesicle vaccine. $V$ accine 13, 401-407.

Pettersson, A., Kuipers, B., Pelzer, M., Verhagen, E., Tiesjema, R. H., Tommassen, J. \& Poolman, J. T. (1990). Monoclonal antibodies against the 70-kilodalton iron-regulated protein of Neisseria meningitidis are bactericidal and strain specific. Infect Immun 58, 3036-3041.

Pettersson, A., Scheper, E., Tommassen, J., Kuipers, B. \& Poolman, J. T. (1991). Heterogeneity of iron-regulated meningococcal $70 \mathrm{kDa}$ and $98 \mathrm{kDa}$ OMPs. In Neisseria 1990 , pp. 459-463. Edited by M. Achtman, P. Kohl, C. Marchal, G. Morelli, A. Seiler \& B. Thiesen. Berlin: Walter de Gruyter.

Pettersson, A., Klarenbeek, V., van Deurzen, J., Poolman, J. T. \& Tommassen, J. (1994). Molecular characterization of the structural gene for the lactoferrin receptor of the meningococcal strain H44/76. Microb Pathog 17, 395-408.

Pettersson, A., Maas, D., van Wassenaar, D., van der Ley, P. \& Tommassen, J. (1995). Molecular characterization of FrpB, the 70kilodalton iron-regulated outer-membrane protein of Neisseria meningitidis. Infect Immun 63, 4181-4184.

Poolman, J. T. (1995). Development of a meningococcal vaccine. Infect Agents Dis 4, 13-28.

Smith, N. H., Maynard Smith, J. \& Spratt, B. G. (1995). Sequence evolution of the porB gene of Neisseria gonorrboeae and Neisseria meningitidis: evidence of positive Darwinian selection. Mol Biol Evol 12, 363-370.

Stojiljkovic, l., Hwa, V., de Saint Martin, L., O'Gaora, P., Nassif, X., Heffron, F. \& So, M. (1995). The Neisseria meningitidis haemoglobin receptor: its role in iron utilization and virulence. Mol Microbiol 15, 531-541.

Vázquez, J. A., Berrón, S., O’Rourke, M., Carpenter, G., Feil, E., Smith, N. H. \& Spratt, B. G. (1995). Interspecies recombination in nature: a meningococcus that has acquired a gonococcal PIB porin. Mol Microbiol 15, 1001-1007.

Wiertz, E. J. H. J., van Gaans-van den Brink, J. A. M., Gausepohl, H., Prochnicka-Chalufour, A., Hoogerhout, P. \& Poolman, J. T. (1992). Identification of $T$ cell epitopes occurring in a meningococcal class 1 outer-membrane protein using overlapping peptides assembled with simultaneous multiple peptide synthesis. $J$ Exp Med 176, 79-88.

Received 15 April 1996; revised 9 July 1996; accepted 15 July 1996. 